\title{
Carbon-based acid catalyst from waste seed shells: preparation and characterization
}

\author{
Li H. Wang1,", Hao Liu', Li Li ${ }^{2}$ \\ ${ }^{1}$ Tianjin Modern Vocational Technology College, Department of Biochemical Engineering, Tianjin 300350, China \\ ${ }^{2}$ Chendu Vocational College of Agricultural Science and Technology, Chendu 611000, China \\ "Corresponding author: e-mail: wanglihui2008@126.com
}

\begin{abstract}
A carbon-based solid acid catalyst was prepared by the sulfonation of carbonized seed shells of Jatropha curcas (J. curcas L). The structure of amorphous carbon consisting of polycyclic aromatic carbon sheets attached a high density of acidic $\mathrm{SO}_{3} \mathrm{H}$ groups $\left(2.0 \mathrm{mmol} \cdot \mathrm{g}^{-1}\right)$ was identified with scanning electron microscopy (SEM), fourier transform infrared (FTIR) spectroscopy, powder X-ray diffraction (XRD), and X-ray photoelectron spectroscopy (XPS) . The performance of the solid acid catalyst was evaluated for biodiesel production in the esterification of oleic acid with methanol. 95.7\% yield of biodiesel was obtained after $2 \mathrm{~h}$ reaction and the conversions with reused catalyst varied in the range of $95.7 \%$ to $95.1 \%$, showing better activity and stability than commercial catalyst amberlyst-46. It was also observed that the prepared catalyst showed enhanced activity in the transesterification of triolein with methanol when compared with other solid acid catalysts. A synergistic effect results from the high density of $\mathrm{SO}_{3} \mathrm{H}$ groups and the good access of reactants to the acidic sites can be used to explain the excellent catalytic activity, as well as the strong affinity between the hydrophilic reactants and the neutral $\mathrm{OH}$ groups bonded to the polycyclic aromatic carbon rings.
\end{abstract}

Keywords: carbon-based solid acid, waste seed shells, esterification, transesterification, biodiesel.

\section{INTRODUCTION}

Biodiesel is an environmentally safe and alternative fuel source, which produced from plant oils, recycled cooking greases or oils, and animal fats ${ }^{1,2}$. Usually, both esterification and transesterification occur in the preparation of biodiesel from raw oils that contain high levels of free fatty acids (FFAs), such as jatropha oil, karanja oil, and animal fats ${ }^{3,4}$. The esterification of FFAs by liquid acid catalysts $\left(\mathrm{H}_{2} \mathrm{SO}_{4}\right)$ is a process commonly used for biodiesel production, but it requires energy intensive separation operations which lead to waste and environmental pollution ${ }^{5}$. Heterogeneous solid acid catalysts have unique advantages in esterification and transesterification reactions. Thus, the use of heterogeneous solid acid catalysts to replace homogeneous ones could eliminate the problems associated with homogeneous catalysts and could enhance the use of high acid value oil to be used as feedstock for synthesis of biodiesel ${ }^{6,7}$. In the last decades, various solid acids (resins, zeolite, sulfated zirconia, polyaniline sulfate, heteropolyacid, metal complexes, sulfated tin oxide, and acidic ionic liquid) have been explored as potential heterogeneous catalysts in the production of biodiesel ${ }^{\mathbf{8}, 9}$. Some common problems, such as low acid site concentrations, hydrophilic character of catalyst surfaces, and active site leaching, have hampered their practical applications. High cost is another obstacle for the commercialization of the above acid catalysts ${ }^{\mathbf{1 0}}$.

Recently, a new class of catalysts derived from incomplete carbonization of simple natural products such as sugar, starch or cellulose, has been reported to have better catalytic performance for esterification of FFAs, and higher stability than other solid acid catalysts. Such environmentally benign alternative catalysts have found applications in various acid-catalysed reactions including esterification, transesterification, and hydrolysis ${ }^{11,}{ }^{12}$.

The rapid growth of biodiesel industry has resulted in an oversupply of byproducts, such as seed shells, oilseed cakes and glycerol. Glycerol and oil asphalt -based heterogeneous catalysts have been reported ${ }^{13,14}$. Activated carbon was also prepared by using various low-cost coconut shell and nut shells ${ }^{15,16}$. However, to the best of our knowledge, there has been no report on carbon-based catalyst prepared from seed shells.

In order to realize the efficient utilization of the byproduct (seed shells), a carbon-based solid acid catalyst derived from waste seed shells was prepared in this study. The catalyst was characterized by SEM, FTIR, XRD and XPS. For the preparation of biodiesel, the catalytic activities of the catalyst in esterification and transesterification were also investigated.

\section{EXPERIMENTAL}

\section{Material}

The seed shells of $J$. curcas L.were collected from local market. The oil of J. curcas L. (average molecular weight was 862.07) was obtained from the Ruifeng Plantation Company, Guizhou Province, China. Amberlyst 46 was purchased from the Dow Chemical Company. Methyl palmitate, methyl stearate, methyl oleate, methyl linoleate, methyl linolenate, methyl heptadecanoate, oleic acid and methanol were purchased from Sigma-Aldrich (USA). All other chemicals and reagents were analytical grade and obtained commercially.

\section{Preparation of carbon-based catalyst}

Firstly, the seed shells were pre-treated to remove water and residual esters. $10 \mathrm{~g}$ of seed shells were carbonized for $5 \mathrm{~h}$ at $350^{\circ} \mathrm{C}$ under $\mathrm{N}_{2}$ flow to produce a brown-black solid. Secondly, the solid was ground to powders and heated in $200 \mathrm{ml}$ of concentrated $\mathrm{H}_{2} \mathrm{SO}_{4}(>96 \%)$ at $100^{\circ} \mathrm{C}$ under an $\mathrm{N}_{2}$ atmosphere. Thirdly, after heating for $8 \mathrm{~h}$ and then cooling to room temperature, $1000 \mathrm{ml}$ of distilled water was added to the mixture to form a black precipitate. The precipitate was cooled to ambient 
temperature and washed with hot water under agitation until the wash water showed a neutral $\mathrm{pH}$ value.

\section{Characterization of carbon-based catalyst}

SEM images of the carbon-based catalyst were recorded by using a Philips XL30 ESEM instrument at $10 \mathrm{kV}$. XRD pattern of the catalyst was obtained on a Philips $X$ 'Pertpro diffractometer using $\mathrm{Co} \mathrm{Ka}$ radiation with an accelerating voltage of $40 \mathrm{kV}$ and current of $40 \mathrm{~mA}$. FTIR spectra of the catalyst were obtained on a Nicolet-560 spectrometer. Thirty two scans were accumulated with a resolution of $4 \mathrm{~cm}^{-1}$ for each spectrum. The surface properties of the catalyst were characterized by XPS in a Perkin-Elmer PHI 1600 ESCA system with a monochromatic $\mathrm{Mg}$ Ka source and a charge neutralizer.

\section{Esterification of free higher fatty acids and transesteri- fication of triolein}

The esterification and transesterification reactions were carried out in a three-neck round bottom flask immersed in a silicon oil bath at $80^{\circ} \mathrm{C}$. For esterification reactions, $0.1 \mathrm{~mol}$ of methanol, $0.1 \mathrm{~mol}$ of oleic acid and $0.14 \mathrm{~g}$ of catalyst were added to the flask. For transesterification of triolein, $0.3 \mathrm{~mol}$ of methanol, $0.01 \mathrm{~mol}$ of $J$. curcas $\mathrm{L}$. seed oil and $0.2 \mathrm{~g}$ of catalyst were added to the flask. After reaction, the catalyst was separated by filtration and washed with methanol for re-use. The contents of biodiesel in the reaction mixture were quantitatively
The SEM image of the prepared solid acid was shown in Figure 2. As can be seen from Figure 2, the solid acid powders were irregular particles. Additionally, the Brunauer-Emmett-Teller (BET) surface area of the catalyst after dehydration was about $6.54 \mathrm{~m}^{2} \mathrm{~g}^{-1}$, which was higher than the cellulose-derived material ${ }^{17}$.

Evidence for the successful preparation of solid acid was also obtained by FTIR experiments (Fig. 3). The vibration bands at $1037 \mathrm{~cm}^{-1}$ and $1367 \mathrm{~cm}^{-1}$ in the FTIR spectrum indicated that the resulting material possesses $\mathrm{SO}_{3} \mathrm{H}$ groups ${ }^{19}$. The peaks at $1727 \mathrm{~cm}^{-1}$ and $1594 \mathrm{~cm}^{-1}$ were assigned to $\mathrm{C}=\mathrm{O}$ and $\mathrm{O}-\mathrm{H}$ vibrations in the catalysts ${ }^{17}$.

Figure 4 showed XRD patterns for the carbonized shells before (Figure 4a) and after (Fig. 4b) sulfonation. The XRD patterns exhibited two broad but weak diffraction peaks at $2 \theta$ angles of $20^{\circ}-30^{\circ}$ and $40^{\circ}-50^{\circ}$, which could attribute to amorphous carbon composed of aromatic carbon sheets oriented in a considerably random fashion ${ }^{20}$.

X-ray photoelectron spectroscopy (XPS) was conducted to investigate the surface element composition of solid acid. As shown in Figure 5a, there were C, O, N, and S element in their XPS survey spectrum. The single peak at $168 \mathrm{eV}$ was assigned to the $\mathrm{SO}_{3} \mathrm{H}$ groups, indicating that sulfonation of amorphous carbon was successfully achieved and all sulfur in the carbon catalyst was contained in the $\mathrm{SO}_{3} \mathrm{H}$ groups ${ }^{21}$ (Fig. 5b). The binding energy

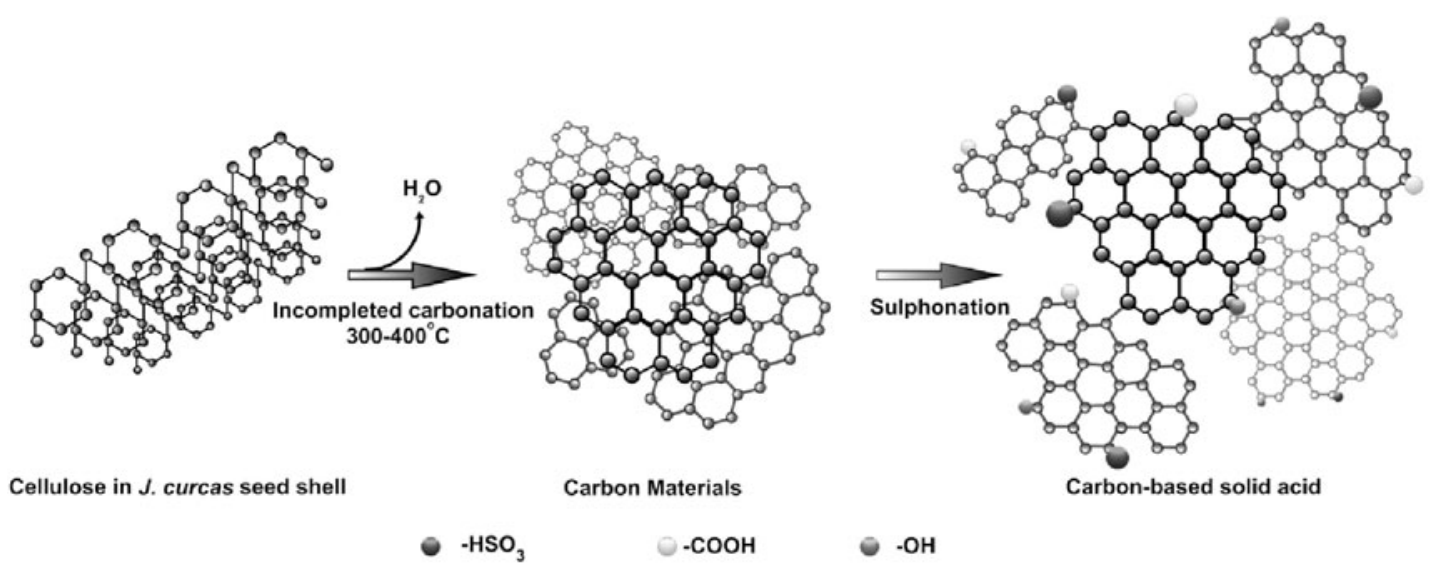

Figure 1. Schematic illustration of the carbon-based solid acid preparation from the $J$. curcas L. seed shell

analyzed by using a gas chromatograph (Beifen Ruili Analytical Instrument Co., Beijing, China) equipped with an SE-30 capillary column $(30 \mathrm{~m} \times 0.25 \mathrm{~mm}$; ZKAT Analytical Technology Co., Lanzhou, China).

\section{RESULTS AND DISCUSSION}

The solid acid catalysts were prepared by carbonization of the seed shells followed by sulfonation, as shown in Figure 1. Firstly, the seed shells were pyrolyzed at $350^{\circ} \mathrm{C}$ (the stage of carbonization), accompanied by dehydration and dissociation of -C-O-C-, leading to the formation of polycyclic aromatic carbon rings and the amorphous carbon structure ${ }^{17,18}$. Secondly, $\mathrm{SO}_{3} \mathrm{H}$ was introduced into the aromatic carbon rings by sulfonation, leading to the formation of solid acid.

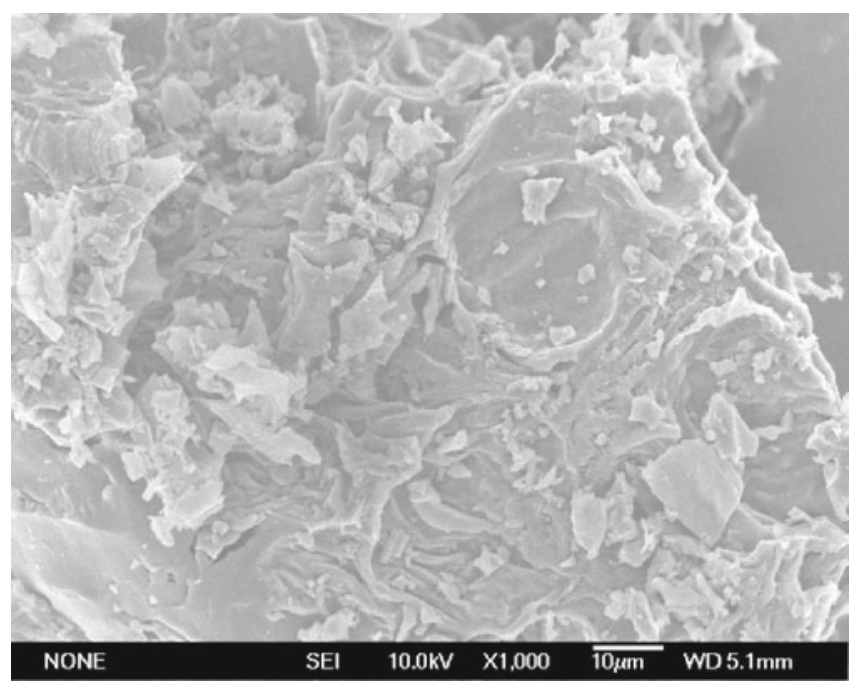

Figure 2. SEM image of J. curcas L seed shell-derived solid acid 


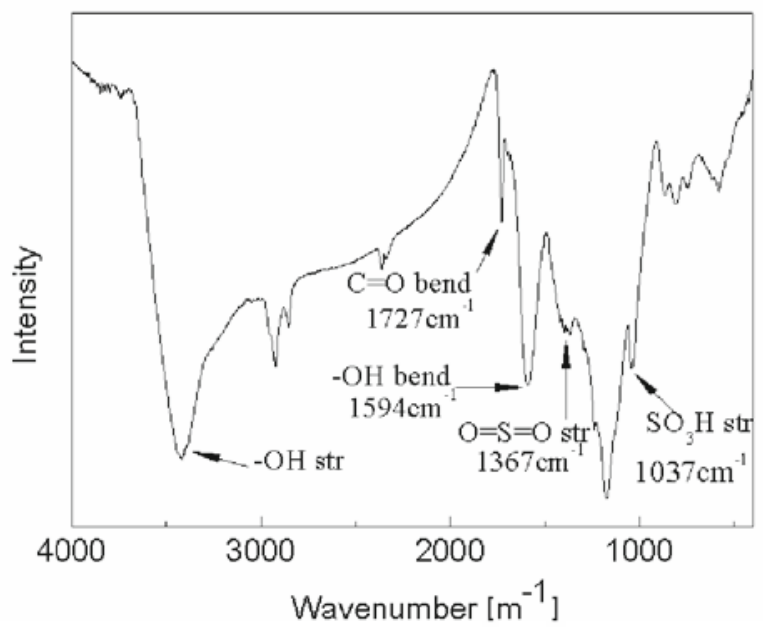

Figure 3. FT-IR spectrum of J. curcas L. seed shell-derived solid acid

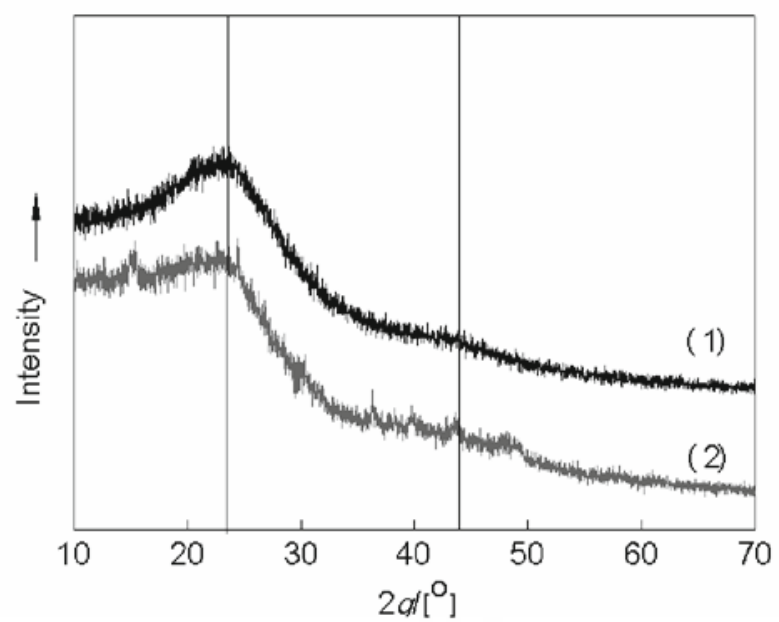

Figure 4. XRD patterns for carbonized shells. (1) before sulfonation; (2) after sulfonation

of $\mathrm{O}(1 \mathrm{~s})$ is deconvoluted on the two components from $\mathrm{O}-\mathrm{I}(\mathrm{S}=\mathrm{O}$ and $\mathrm{C}=\mathrm{O})$ and $\mathrm{O}-\mathrm{II}(\mathrm{S}-\mathrm{O}$ and $\mathrm{C}-\mathrm{O})$ shifts up as the $\mathrm{SO}_{3} \mathrm{H}$ impregnation, indicating that the acidity increases together with the degree of impregnation ${ }^{22}$. The $\mathrm{SO}_{3} \mathrm{H}$ attached to the aromatic carbon atoms was up to $2.0 \mathrm{mmol} \cdot \mathrm{g}^{-1}$ and gave the two forms $\mathrm{S}=\mathrm{O}$ and $\mathrm{S}-\mathrm{O}$ in $2: 1$ ratio. All these results indicate that this solid acid catalyst is amorphous carbon consisting of polycyclic aromatic carbon sheets attached a high density of acid sites functioned as catalytic center'. Consistent with the high density of acid sites and binding energy of $\mathrm{O}(1 \mathrm{~s})$, the solid acid's catalytic activity also proportionally increases ${ }^{9}$.

The catalyst was evaluated in the esterification of oleic acid and methanol for the production of biodiesel
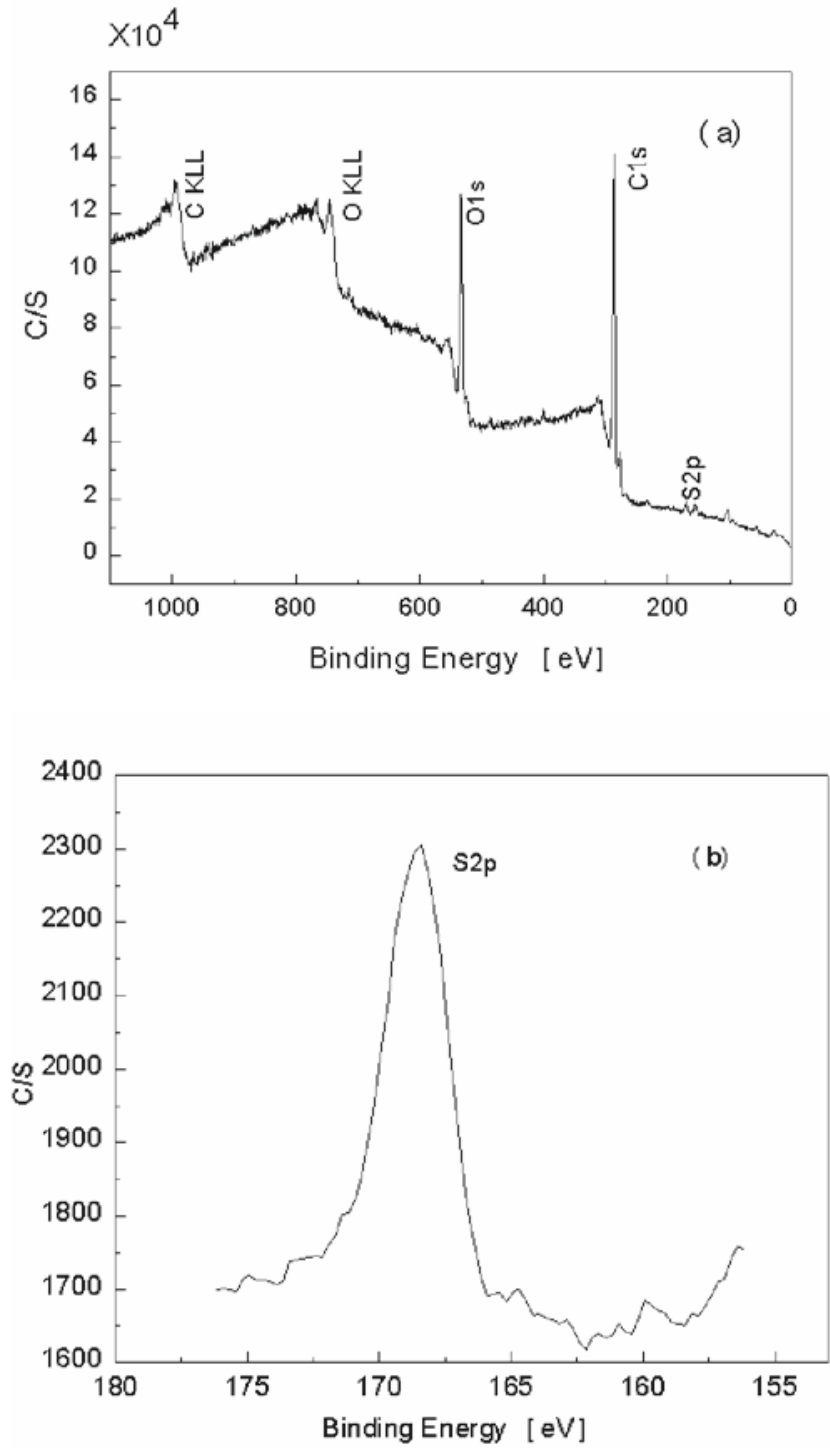

Figure 5. (a) XPS survey spectrum of the seed shell-derived solid acid; (b) high-resolution spectrum of S2p of the seed shell-derived solid acid

at $80^{\circ} \mathrm{C}$. As can be seen in Table 1 , the yield of methyl oleate reached ca. $80 \%$ within $30 \mathrm{~min}$ and increased to more than $90 \%$ within $2 \mathrm{~h}$ in the presence of the seed shell carbon-based solid acids. The commercial catalyst amberlyst- 46 was also tested in this reaction and the yields of methyl oleate were $21.7 \%$ within $30 \mathrm{~min}$ and $77.5 \%$ within $2 \mathrm{~h}$. Additionally, the recycle of the catalyst was tried for 4 times to study its activity and stability. After the first reaction run, the catalyst was separated from the reaction mixture and then washed with methanol. After drying, the catalysts were used for the next run at identical conditions. Table 1 also showed that both the catalysts were still active in each recycle run and

Table 1. Esterification catalyzed by J. curcas L. seed shell-derived solid acid and Amberlyst 46

\begin{tabular}{|l|c|c|c|c|}
\hline \multirow{2}{*}{ Methyl Oleate yield [\%] } & \multicolumn{2}{|c|}{ J. curcas L. seed shell-derived solid acids* } & \multicolumn{3}{|c|}{ Amberlyst 46* } \\
\cline { 2 - 5 } & $30 \mathrm{~min}$ & $2 \mathrm{~h}$ & $30 \mathrm{~min}$ & 77.5 \\
\hline 1 & 82.8 & 95.7 & 21.7 & 78.1 \\
\hline 2 & 80.5 & 92.9 & 22.0 & 77.9 \\
\hline 4 & 83.7 & 94.3 & 21.9 & 77.2 \\
\hline
\end{tabular}

${ }^{*}$ Catalyst: $0.14 \mathrm{~g}$, oleic acid: $0.1 \mathrm{~mol}$, methanol: $0.1 \mathrm{~mol}$, reaction temperature: $80^{\circ} \mathrm{C}$, reaction time: $2 \mathrm{~h}$. 
Table 2. Transesterification catalyzed by solid acids

\begin{tabular}{|c|c|c|c|}
\hline Catalyst & $\mathrm{SO}_{3} \mathrm{H}$ density $\left[\mathrm{mmol} \cdot \mathrm{g}^{-1}\right]$ & FAMEs yield [\%] & Turnover Frequency $\left[\mathrm{h}^{-1}\right]$ \\
\hline J. curcas L. seed shell-derived solid acid & 2.0 & 31.5 & 1.31 \\
\hline Cellulose derived carbon-based solid acid* & 1.2 & 24.1 & 1.67 \\
\hline Amberlyst- $46^{*}$ & 1.3 & 17.2 & 1.10 \\
\hline Amberlyst-15* & 4.9 & 5.0 & 0.085 \\
\hline Nafion NR50* & 0.9 & 1.5 & 0.139 \\
\hline Nafion $/ \mathrm{SiO}_{2}{ }^{*}$ & 0.1 & 1.1 & 0.917 \\
\hline
\end{tabular}

${ }^{*}$ Catalyst: $0.2 \mathrm{~g}$, triolein: $0.01 \mathrm{~mol}$, methanol: $0.3 \mathrm{~mol}$, reaction temperature: $80^{\circ} \mathrm{C}$, reaction time: $6 \mathrm{~h}^{17}$.

no obvious activity decrease was observed after 4 times reuses. The maximum turnover frequency (TOF) of seed shell-derived solid acid $\left(597.9 \mathrm{~h}^{-1}\right)$ was much higher than that of amberlyst-46 $\left(241.8 \mathrm{~h}^{-1}\right)$, which can be attributed to the difference of density of acid active sites. In all cases, the selectivities to methyl oleate catalyzed by seed shell-derived solid acid were observed to be $>98 \%$.

The solid acid also showed high catalytic performance for the transesterification of triolein (such as J. curcas L. seed oil), as compared with other tested solid Brønsted acid catalysts (Table 2). The conversion of triolein catalyzed by the solid acid was $85 \%$ and the selectivity of methyl oleate was $37.1 \%$. This high catalytic performance cannot be adequately explained simply by the high density of $\mathrm{SO}_{3} \mathrm{H}$ groups and good access of reactants to the $\mathrm{SO}_{3} \mathrm{H}$ groups. The transesterification reaction involves alcohols which are hydrophilic molecules. The strong affinity between the hydrophilic parts of the reactants and the almost neutral $\mathrm{OH}$ groups bonded to the polycyclic aromatic carbon rings may contribute to the high catalytic performance of the solid acid. These results were similar with previous reports ${ }^{17}$. Additionally, the high density of strongly acidic $\mathrm{SO}_{3} \mathrm{H}$ groups and good access of reactants to the $\mathrm{SO}_{3} \mathrm{H}$ groups are also beneficial for the high catalytic performance.

\section{CONCLUSIONS}

In conclusion, an effective, inexpensive and reusable carbon-based catalyst derived from waste seed shells was prepared in this study. The results indicated that this catalyst showed higher catalytic activity than other solid acid as catalyst for efficient production of biodiesel. In addition to biodiesel production, such catalyst would find applications in a wide range of other acid-catalyzed reactions.

\section{LITERATURE CITED}

1. Karmakar, A., Karmakar, S. \& Mukherjee, S. (2010). Properties of various plants and animals feedstocks for biodiesel production. Bioresour. Technol. 101(19), 7201-7210. DOI: 10.1016/j.biortech.2010.04.079.

2. Chavez, E., Liu, D. \& Zhao, X.B. (2010). Biofuels Production Development and Prospects in China. J. Biobased Mater. Bio. 4(3), 221-242. DOI: 10.1166/jbmb.2010.1088.

3. Ramadhas, A.S., Jayaraj, S. \& Muraleedharan, C. (2005). Biodiesel production from high FFA rubber seed oil. Fuel 84(4), 335-340. DOI: 10.1016/j.fuel.2004.09.016.

4. Avhad, M. \& Marchetti, J. (2015). A review on recent advancement in catalytic materials for biodiesel production. Renew. Sust. Energ. Rev. 50(1), 696-718. DOI: 10.1016/j. rser.2015.05.038.
5. Ding, J.C., He, B.Q. \& Li, J.X. (2011). Cation Ion-Exchange Resin/Polyethersulfone Hybrid Catalytic Membrane for Biodiesel Production. J. Biobased Mater. Bio. 5(1), 85-91. DOI: 10.1166/jbmb.2011.1125.

6. Boz, N., Degirmenbasi, N. \& Kalyon, D. (2015). Esterification and Transesterification of Waste Cooking Oil over Amberlyst 15 and Modified Amberlyst 15 Catalysts. Appl. Catal. B-Environ. 165(14), 723-730. DOI: 10.1016/j. apcatb.2014.10.079.

7. Kulkarni, M.G., Gopinath, R., Meher, L.C. \& Dalai, A.K. (2006). Solid acid catalyzed biodiesel production by simultaneous esterification and transesterification. Green Chem. 8(12), 1056-1062. DOI: 10.1039/B605713F.

8. Rao, K.N., Sridhar, A., Lee, A.F., Tavener, S.J., Young, N.A. \& Wilson, K. (2006). Zirconium phosphate supported tungsten oxide solid acid catalysts for the esterification of palmitic acid. Green Chem. 8(9), 790-797. DOI: 10.1039/ B606088A.

9. Yan, S., Maggio, C.D., Mohan, S., Kim, M., Salley, S.O. \& Simon, Ng K.Y. (2010). Advancements in Heterogeneous Catalysis for Biodiesel Synthesis. Top Catal. 53(11-12), 721-736. DOI: 10.1007/s11244-010-9460-5.

10. Gupta, P. \& Paul, S. (2014). Solid acids: Green alternatives for acid catalysis. Catal. Today. 116(2), 153-170. DOI: 10.1016/j.cattod.2014.04.010.

11. Mo, X.H., Lotero, E., Lu, C.Q., Liu, Y.L. \& Goodwin, J.G. (2008). A Novel Sulfonated Carbon Composite Solid Acid Catalyst for Biodiesel Synthesis. Catal. Lett. 123(1-2), 1-6. DOI: $10.1007 / \mathrm{s} 10562-008-9456-\mathrm{y}$.

12. Sania, Y., Dauda, W. \& Aziza, A. (2014). Solid acids: Green alternatives for acid catalysis. Appl. Catal. A-Gen. 470(9), 140-161. DOI: 10.1016/j.apcata.2013.10.052.

13. Devi, B.L.A.P., Gangadhar, K.N., Prasad, P.S.S., Jagannadh, B. \& Prasad, R.B.N. (2009). A Glycerol-based Carbon Catalyst for the Preparation of Biodiesel. Chem. Sus. Chem. 2(7), 617-620. DOI: 10.1002/cssc.200900097.

14. Shu, Q., Zhang, Q., Xu, G.H., Nawaz, Z., Wang, D.Z. \& Wang, J.F. (2009). Synthesis of biodiesel from cottonseed oil and methanol using a carbon-based solid acid catalyst. Fuel Process Technol. 90, 1002-1008. DOI: 10.1016/j.fuproc.2009.03.007.

15. Sricharoenchaikul, V., Pechyen, C. \& Aton, D. (2008). Preparation and Characterization of Activated Carbon from the Pyrolysis of Physic Nut (Jatropha curcas L.) Waste. Energ. Fuel. 22(1), 31-37. DOI: 10.1021/ef700285u.

16. Suárez-García, F., Martínez-Alonso, A. \& Tascón, J.M.D. (2001). Porous texture of activated carbons prepared by phosphoric acid activation of apple pulp. Carbon. 39(7), 1111-1115. DOI: 10.1016/S0008-6223(01)00053-7.

17. Hara, M. (2010). Biodiesel Production by Amorphous Carbon Bearing $\mathrm{SO}_{3} \mathrm{H}, \mathrm{COOH}$ and Phenolic $\mathrm{OH}$ Groups, a Solid Brønsted Acid Catalyst. Top Catal. 53(11-12), 805-810. DOI: $10.1007 / \mathrm{s} 11244-010-9458-\mathrm{z}$.

18. Samart, C., Karnjanakom, S., Chaiya, C., Reubroycharoen, P., Sawangkeawd, R. \& Charoenpaniche, M. (2015). Statistical optimization of biodiesel production from para 
rubber seed oil by $\mathrm{SO}_{3} \mathrm{H}-\mathrm{MCM}-41$ catalyst. Arab. J. Chem. In Press. DOI: 10.1016/j.arabjc.2014.12.034.

19. Li, X.T., Jiang, Y.J., Shuai, L., Wang, L.L., Meng, L.Q. \& $\mathrm{Mu}, \mathrm{X}$.D. (2012). Sulfonated copolymers with $\mathrm{SO}_{3} \mathrm{H}$ and $\mathrm{COOH}$ groups for the hydrolysis of polysaccharides. $\mathrm{J} . \mathrm{Ma}$ ter. Chem. 22(1), 1283-1289. DOI: 10.1039/C1JM12954F.

20. Nakajima, K., Hara, M. \& Hayashi, S. (2007). Environmentally Benign Production of Chemicals and Energy Using a Carbon-Based Strong Solid Acid. J. Am. Ceram Soc. 90(12), 3725-3734. DOI: 10.1111/j.1551-2916.2007.02082.x.

21. Suganuma, S., Nakajima, K., Kitano, M., Yamaguchi, D., Kato, H., Hayashi, S. \& Hara, M. (2010). Synthesis and acid catalysis of cellulose-derived carbon-based solid acid. Solid State Sci. 12(6), 1029-1034. DOI: 10.1016/j.solidstatesciences.2010.02.038.

22. Vitaliy, E., Alexander, N., Liudmyla, M., Andrii, V. \& Vladyslav, V. (2012). Efficient carbon-based acid catalysts for the propan-2-ol dehydration. Catal. Commun. 27(5), 33-37. DOI: 10.1016/j.catcom.2012.06.018. 